\title{
Counter Flow Adiabatic Regenerator and Comparative Study
}

\author{
I. P. Koronaki*, R. I. Christodoulaki, V. D. Papaefthimiou, E. D. Rogdakis \\ Laboratory of Applied Thermodynamics - School of Mechanical Engineering, Thermal Engineering Section \\ National Technical University of Athens \\ Heroon Polytechniou 9, Zografou Campus 15780, Athens, Greece \\ E-mail: koronaki@central.ntua.gr, rchris@central.ntua.gr, vpapaeft@central.ntua.gr, rogdemma@central.ntua.gr
}

Received 31 October 2014, Revised 18 January 2015, Accepted 17 February 2015

\begin{abstract}
Liquid desiccant air conditioning systems have recently been attracting attention due to their capability of handling the latent load without super-cooling and then reheating the air, as happens in a conventional compression-type air conditioning system. This paper presents the results from a performance study of the simultaneous heat and mass transfer between air and liquid desiccant in an adiabatic, counter flow, structured packed regenerator. A heat and mass transfer numerical model has been developed, based on the Runge-Kutta non-stiff fixed step method, to predict the performance of the device under various operating conditions. Good agreement was found between the theoretical model and experimental tests from previous studies, with the deviation range being $\pm 6.2 \%$ in air outlet temperature, $\pm 8.1 \%$ in air outlet humidity ratio and $\pm 1.4 \%$ in solution outlet temperature. Important design variables are also defined. The effects of air and desiccant flow rates, air humidity ratio, desiccant temperature and concentration have been reported on the regeneration rate and regeneration effectiveness. A detailed sensitivity analysis has been implemented to indicate which input variables mostly affect the output conditions. The three most commonly used liquid desiccant solutions, namely $\mathrm{LiCl}, \mathrm{LiBr}$ and $\mathrm{CaCl}_{2}$ were evaluated against each other. The results show that high regeneration efficiency could be achieved under high desiccant mass flow rates, high air mass flow rate, high desiccant inlet temperature, low desiccant inlet concentration and $\mathrm{CaCl}_{2}$ as the desiccant solution.
\end{abstract}

Keywords: Liquid desiccant; adiabatic regeneration; packed column.

\section{Introduction}

Thermally driven liquid desiccant cooling systems have emerged as a potential alternative to conventional vapor compression systems for cooling and air conditioning. The principle of their operation has been known for years. In the dehumidification process, the strong desiccant solution that has been brought into contact with the air absorbs the moisture from the air and gets diluted. After that, the desiccant must be regenerated to a useful level of concentration.

The regenerator is one of the most significant heat and mass transfer components in a liquid desiccant airconditioning system, whose efficiency directly influences the system performance [1,2,3]. The largest energy requirement associated with the liquid desiccant system is the heat required for desiccant regeneration, so the effectiveness of the desiccant regeneration process greatly influences the overall system performance. The regeneration of liquid desiccant can be driven by solar energy, waste heat or other low-grade heat source [4].

Several literatures have been dedicated to the investigation of the performance of liquid desiccant dehumidifiers and regenerators [5-10], while others have experimentally tested the heat and mass transfer performances in the dehumidification/regeneration process [11-18].

There are three main solutions to predict the heat and mass transfer performance of a packed-type dehumidifier/regenerator; the finite difference model $\quad[19$,
20], the effectiveness NTU model [21] and the model based on fitted algebraic equations [22, 23].

The finite difference model, which is based on fundamental equations and gives a numerical solution, works well when the processed air and liquid desiccant are in parallel flow [24]. Indeed, the finite difference model developed by Elsayed et al [25] could predict the heat and mass transfer in packed beds during the air dehumidification mode and the solution regeneration mode. The most commonly accepted and widely used model is the onedimensional finite difference model developed by Factor and Grossman [20]. Good agreement also exists between the experimental findings and the finite difference model predictions developed by Martin and Goswami [26]. The adapted finite difference model of Fumo and Goswami [6] shows very good agreement with the experimental findings. Ren et al [27] found a close agreement between the experimental results and the predictions of the finite difference model when using different heat and mass transfer coefficients. Babakhani and Soleymani [28] developed a finite difference analytical solution of heat and mass transfer processes in a packed bed liquid desiccant regenerator, suitable for high desiccant flow rate, both for random and structured packings. When compared with reliable experimental data, the model results had a maximum difference of $6 \%$.

However, in the counter-flow configuration, which is the most commonly used flow pattern for a liquid desiccant dehumidifier/regenerator, the outlet conditions of the 
desiccant are unknown. An iterative solution is thus necessary, until the results converge to the known inlet conditions [24]. Thus, the effectiveness NTU model [21] and the model based on fitted algebraic equations [22,23] are used. Gandhidasan [29] developed a simplified model for the preliminary design of an air dehumidification process. Lof et al [13] studied the reconcentration of a $\mathrm{LiCl}$ solution in a solar air collector and used experimental data for a counter flow packed regenerator to verify the mass transfer and heat transfer coefficients. Gandhidasan et al [7] demonstrated the performance differences between different packing types inside a counter flow packed column using $\mathrm{CaCl}_{2}$. Lazzarin et al [8] investigated both theoretically and experimentally the optimum operative conditions in a counter flow packed tower using $\mathrm{LiBr}$ and $\mathrm{CaCl}_{2}$. Raisul Islam et al. [30] validated a simplified linear coupled heat and mass transfer model for $\mathrm{LiBr}$ counter-flow absorbers against a numerical turbulent flow model, achieving deviations between 4.2-9.2\%. Chen et al [24] presented an integrated analytical solution of adiabatic heat and mass transfer in packed-type liquid desiccant system, in both parallel-flow and counter-flow configurations. This analytical solution suited only high desiccant flow rate conditions, since the desiccant concentration was assumed to be constant throughout the absorber/regenerator. Based on the work of Factor and Grossman [20], Chengqin et al [31] developed a controlling equation for the quasi-equilibrium conditions of the two fluid streams. Numerical simulations of one dimensional heat and mass transfer model under practical conditions were performed, by dividing the heat and mass transfer area into a number of control volumes. A validated integrated analytical solution of an adiabatic liquid desiccant system is adopted by Xiao et al [32]. The analytical solution, suitable for high desiccant flow rate conditions, showed that the system experiences higher COP when the ambient air temperature and moisture content are higher. Audah et al [33] studied a solar-powered liquid desiccant system in Beirut using parabolic solar concentrators as a heat source for regenerating the liquid desiccant. Although their results agree well with the literature, their fourth order Runge-Kutta model used previously developed mathematical models and assumed constant heat and mass transfer coefficients. An analytical solution method was put forward by Peng et al [34] to predict the performance of solar collector / regenerator, based on the correlative assumptions and proved validity by comparing with numerical solution method and experiments. Though the results of numerical and analytical solution agree well, the errors between both still exist; for the outlet concentration, the relative error between the numerical and analytical solutions was $2.7-9.7 \%$.

In the present work, a numerical model has been derived that permits reliable prediction of the regenerator efficiency of an adiabatic counter flow packed column. The advantage of this model is its ability to easily adapt under different operational conditions, different flow configurations (parallel or counter) and different liquid desiccant solutions (salts or glycols). Utilizing the arithmetic method of RungeKutta, the model not only produces the outlet values of air and solution, but it is able to predict also the conditions along the height of the device. Fumo and Goswami $[5,6]$ experimental data for $\mathrm{LiCl}$ solution were used to verify the theoretical model. Another innovation of this research lies in the comparison of the regeneration potential between more than two liquid desiccant solutions; namely $\mathrm{LiCl}-\mathrm{H}_{2} \mathrm{O}, \mathrm{LiBr}-$ $\mathrm{H}_{2} \mathrm{O}$ and $\mathrm{CaCl}_{2}-\mathrm{H}_{2} \mathrm{O}$. Vapor pressure expressions for each desiccant solution were obtained from the work of Cisternas and Lam $[35,36]$.

\section{Method \\ 2.1 Model Description}

The numerical model was developed as an extension of Rogdakis et al [37] and Papaefthimiou et al [38,39] work. The scope of this approach was to develop a model that minimizes the computational time without sacrificing the accuracy, with the view to use it as a simulation tool in real installations. Thus, based on the energy and mass conservation laws, the developed numerical model describes the coupled heat and mass transfer processes taking place inside a counter-flow (upward air flow and downward desiccant flow) packed column liquid desiccant regenerator.

The packed column height $\mathrm{Z}$ is divided into equal segments and the mass and energy balances are solved for each segment. These calculations start at the top of the column, $Z=0$ until the bottom of the column $Z=1$. Thus, gradients of air temperature, humidity ratio, desiccant temperature, desiccant flow rate and concentration are calculated across the height of the column. In order to begin calculations, the following initial parameters have been set:

- Temperature of ambient air

- Humidity ratio of ambient air

- Flow rate of air inlet

- Physical properties of ambient air

- Temperature of desiccant solution inlet

- Concentration of desiccant solution inlet

- Flow rate of inlet desiccant

- Lewis number

- Heat and mass transfer area of regenerator.

The developed numerical model was then validated against experimental data taken from Fumo and Goswami $[5,6]$.

\subsection{Overview of the Parametric Study}

Following the validation of the numerical model, an extensive theoretical investigation was conducted to examine the effects of various operating parameters on the regeneration efficiency of the adiabatic packed column regenerator. The investigation included three commonly used liquid desiccant solutions; $\mathrm{LiCl}-\mathrm{H}_{2} \mathrm{O}, \mathrm{LiBr}-\mathrm{H}_{2} \mathrm{O}$ and $\mathrm{CaCl}_{2}-\mathrm{H}_{2} \mathrm{O}$. All the inlet conditions are described in Table 1 .

Table 1. Inlet values for the parametric analysis.

\begin{tabular}{ll}
\hline \multicolumn{2}{c}{ Variation of inlet conditions } \\
\hline Variation of inlet air temperature & $30,32,34,36$, \\
$T_{\mathrm{a}}$, in oC & $38,40,42$ \\
Variation of inlet humidity ratio $^{-1}$ & $0.01086,0.01286,0.01486$, \\
$W_{\mathrm{a}}$,in kg kg & \\
Variation of inlet air mass flow $^{\text {rate ma kg s-1 }}$ & $0.01686,0.01886$ \\
& $0.03265,0.04898,0.0653$, \\
& $0.08162,0.09795,0.11427$, \\
Variation of inlet solution & 0.1306 \\
temperature $T_{\mathrm{s}}, \mathrm{in}$ oC & $50,55,60,65,70,75,80$ \\
Variation of inlet solution & \\
concentration $X$ kg salt kg solution & -1 \\
Variation of inlet solution mass flow & $0.28,0.3,0.32,0.340 .36$ \\
rate ma kg s-1 & $0.653,0.43533,0.3265,0.2612$, \\
\hline
\end{tabular}

The comparison of the three different liquid desiccant solutions, in terms of their regeneration potential, is implemented also through the evaluation of the loads. The developed computational program can predict the 
distribution of the loads along the regenerator's height. The study of loads was implemented with the starting values:

$T_{\mathrm{a}, \text { in }}=36^{\circ} \mathrm{C}, \quad W_{\mathrm{a}, \text { in }}=0.01486 \mathrm{~kg}_{\mathrm{w}} / \mathrm{kg}_{\mathrm{da}}, \quad \dot{m}_{a}=0.0653 \mathrm{~kg} / \mathrm{sec}$, $T_{\mathrm{s}, \mathrm{in}}=65^{\circ} \mathrm{C}, \dot{m}_{s}=0.3265 \mathrm{~kg} / \mathrm{sec}$ and $X=30 \%$.

\section{Calculation: Heat and Mass Transfer Model of the Packed Column Regenerator \\ 3.1 General Outline}

In this research, two different geometries of the apparatus have been considered; the first one serves the model validation and the second serves the parametric analysis.

Since the developed mathematical model has been validated against experimental data taken from Fumo and Goswami [5,6] the physical dimensions of the model should be the same with the experimental apparatus of Fumo and Goswami [5,6]. In this case, the regenerator consists of a packed column of $\mathrm{d}=0.254 \mathrm{~m}$ diameter $(0.24 \mathrm{~m}$ internal diameter) and $\mathrm{L}=0.6 \mathrm{~m}$ depth. The packing used was polypropylene Rauschert Hiflow rings with specific surface area $\alpha=210 \mathrm{~m}^{2} / \mathrm{m}^{3}$ and the desiccant solution was $\mathrm{LiCl}-\mathrm{H}_{2} \mathrm{O}$. Contrary to the Fumo and Goswami $[5,6]$, no correction factor has been used in the model to account for the reduction of area for mass transfer in the contact column.

Since this research was conducted as an extension of the authors' previous work [38], the geometry and the initial conditions for the parametric study should remain the same, where possible. Therefore, in this case, the regenerator column has $d=0.1524 \mathrm{~m}$ internal diameter and $L=0.41 \mathrm{~m}$ depth. The PVC structured packing has a specific surface $\alpha$ $=\mathrm{m}^{2} / \mathrm{m}^{3}$. The schematic diagram of the counter-flow packed column regenerator is shown in Figure 1.

In order to simplify the complexity of the configuration, the assumptions used in the calculations are:

- Adiabatic regeneration process,

- One-dimensional analysis: heat and mass transfer occur only in the flow direction,

- Uniform flooding of the regenerator and heat transfer area equal to the mass transfer area; thus, transfer area equal to the specific surface area of the packing,

- Vapor pressure equilibrium between the vapor and the liquid at the interface,

- Laminar desiccant flow,

- Negligible radiation heat transfer, due to small temperature differences of the process.

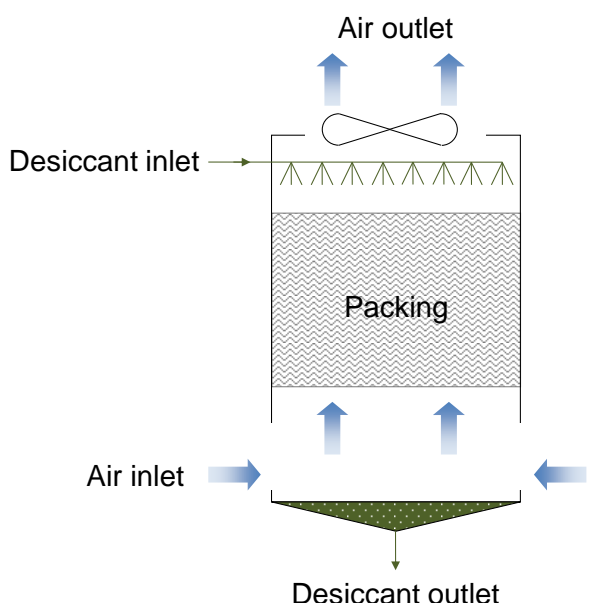

Figure 1. Schematic diagram of the counter-flow packed column regenerator.

\subsection{Thermodynamic Regeneration \\ Parameters Influencing}

Vapor pressure, heat of evaporation, heat and mass transfer coefficients and pressure drop are the most important parameters influencing the regeneration potential of every liquid desiccant solution. Since it would be less accurate to ignore their role and simply assume a constant value, this numerical model has considered their variation with initial conditions, by using expressions taken from literature.

\subsubsection{Vapor Pressure}

The difference between the vapor pressure of the desiccant and the partial pressure of water vapor in the air is the actual driving force for the mass transfer between the liquid desiccant solution and the air [29]. During regeneration, moisture transfer takes place from the desiccant solution to the air only when the desiccant's equilibrium water vapor pressure is higher than the water vapor pressure in the air.

An expression relating the water partial vapor pressure of the desiccant solution with the temperature and the desiccant concentration has been already developed by Fumo and Goswami [5,6], based on the work of Uemura [40,41] and was used for the validation of the mathematical model.

Since though the parametric analysis includes the comparison of three different desiccant solutions, it necessitates the use of an expression that would be commonly valid for all solutions and that would have been developed under the same procedure. Unfortunately, the vapor pressure expressions that Uemura $[40,41]$ developed are valid only for $\mathrm{LiCl}$ and $\mathrm{LiBr}$. Only Cisternas and Lam $[35,36]$, based on Kumar and Patwardhan's [42, 43] method, have developed the needed expression. Thus, the parametric analysis of the present study uses the analytic correlations of Cisternas and Lam $[35,36]$ for the vapor pressure.

After obtaining the vapor pressure correlation equations, the equivalent humidity ratio of liquid desiccant $W^{\text {sat }}\left(T_{s}\right)$ can then be calculated with the equilibrium state of air, as shown in the following equation:

$W^{s a t}\left(T_{s}\right)=0.622 \frac{p_{w, s}^{s a t}\left(T_{s}\right)}{p_{a t m}-p_{w, s t}^{\text {sat }}\left(T_{s}\right)}$

\subsubsection{Heat of Evaporation}

During regeneration (desorption procedure), water vapor molecules of the liquid desiccant solution evaporate from the liquid-vapor interface and are transferred to the process air. The heat of evaporation expresses the energy required to transform a given quantity of moisture into gas at a given pressure. Thus, the energy required for the evaporation of 1 $\mathrm{kg}$ of water from the desiccant solution is expressed by the heat of evaporation, given by the following expression [37]:

$\Delta h_{\text {evap }}=h_{v}\left(p, T_{s}\right)-h_{w, s}\left(T_{s}, X\right)$

\subsubsection{Heat and Mass Transfer Coefficients}

Correlations for the mass transfer coefficients obtained for packed column desiccant air dehumidifiers/regenerators are available in the literature. Onda et al [44] developed empirical correlations for the gas and liquid phase mass transfer coefficients, applicable for random packings with organic solvents. When aqueous salt solutions are used, the liquid phase heat transfer correlation includes errors of $20 \%$. 
Gandhidasan et al [7] calculated the heat and mass transfer coefficients in a $\mathrm{CaCl}_{2}$ liquid desiccant system with random packing. Lof et al [13] used random packing to compare the experimental values of heat transfer coefficients with theoretical values based on McAdams relationship. He found though an average deviation of $\pm 15 \%$ at high liquid flow rates and of $\pm 30 \%$ at lower liquid flow rates. Potnis and Lenz [11] developed dimensionless liquid phase mass transfer correlations, based on experimental results with structured and random packings, using $\mathrm{LiBr}$. Their correlation can predict experimental values within a $20 \%$ range, under low liquid flow rates.

However, in the present investigation, heat and mass transfer correlations that would be applicable for both structured and random packings, as well as for various types of desiccant solutions, are necessary. Therefore, the empirical correlations of Chung and Ghosh [15], based on Treybal [45] and Buckingham Pi method, were used since they are able to predict experimental data within $\pm 10 \%$ for a wide range of operating conditions.

The overall mass transfer correlation for structured packing is:

$$
\mathrm{K}_{G} a\left(\frac{M_{w} d_{e q}{ }^{2}}{D_{\alpha} \rho_{\alpha}}\right)=2.25 \cdot 10^{-4}(1-X)^{-0.75}\left(\frac{\dot{m}_{s}}{\dot{m}_{a}}\right)^{0.1} S c^{0.333} \operatorname{Re}_{a}
$$
is:

The overall mass transfer correlation for random packing

$$
K_{G} a\left(\frac{M_{w} d_{p a c k}^{2}}{D_{\alpha} \rho_{\alpha}}\right)=1.326 \cdot 10^{-4}(1-X)^{-0.94}\left(\frac{\dot{m}_{s}}{\dot{m}_{a}}\right)^{0.27} S c^{0.333} \operatorname{Re}_{a}^{1.16}
$$

\section{Where}

$$
\Delta S c=\frac{\mu_{a}}{D \rho_{a}}, \operatorname{Re}_{a}=\frac{d \rho_{a} V_{a}}{\mu_{a}}
$$

And from Treybal [45]:

$$
d=\frac{6(1-\varepsilon)}{a}
$$

The overall heat transfer correlation is:

$$
h_{G}=L e K_{G} C_{p, m a}
$$

\subsubsection{Pressure Drop}

Many investigators acknowledge the disadvantage of a high pressure drop through the packed bed regenerator, since the pressure drop directly relates the power consumed by the fan [46]. Apart from the packing and the bed physical characteristics, the pressure drop depends also on the desiccant and air mass flow rates [46]. The optimization of the flow rates is very important, since it may deliver more cooling with a pressure drop less than one half than that of a conventional system [47]. The pressure drop equation is given by Gandhidasan [46]:

$\Delta p_{\text {drybed }}=0.125\left(\frac{c_{1}}{\operatorname{Re}_{a}}+\frac{c_{2}}{\operatorname{Re}_{a}^{0.5}}+c_{3}\right) \frac{\rho_{a} V_{a}^{2} a}{\varepsilon^{4.65}}$

\subsection{Energy Balances}

\subsubsection{Air-Desiccant Interface}

By definition, the humidity ratio is given by the following equation:

$W=\frac{\dot{m}_{w}}{\dot{m}_{a}}$

or after differentiating with dz:

$\frac{d \dot{m}_{w}}{d z}=\dot{m}_{a} \frac{d W}{d z}$

During regeneration however, the amount of moisture that is evaporated from the solution is transferred to the air, so:

$d \dot{m}_{s}=d \dot{m}_{w}$

So, the mass flow rate of the desiccant solution is given by the following expression:

$\frac{d \dot{m}_{s}}{d z}=\dot{m}_{a} \frac{d W}{d z}$

The mass balance equation for the liquid desiccant solution gives:

$d\left(\dot{m}_{s} X\right)=0$

Differentiating this equation over height $\mathrm{dz}$ and using Eq. (12), the concentration of the solution is obtained:

$\frac{d X}{d z}=-\frac{\dot{m}_{a}}{\dot{m}_{s}} X \frac{d W}{d z}$

The gradient of humidity ratio along column height expresses the rate of water vapour that is evaporated from the desiccant at the interface within height $\mathrm{dz}$ and can be expressed as follows:

$\frac{d W}{d z}=\frac{L K_{G}}{\dot{m}_{a}}\left(W^{\mathrm{sat}}-W_{i n}\right)$

where $W^{\text {sat }}$ is the humidity ratio of the saturated air that is in equilibrium with the desiccant solution at the local solution temperature and concentration.

\subsubsection{Air Phase}

Figure 2 represents the energy and mass balance in an adiabatic counter flow regenerator. Accordingly,

$\dot{m}_{a} h_{a}+d Q_{S}+d Q_{L}=\dot{m}_{a}\left(h_{a}+d h_{a}\right) \Rightarrow \dot{m}_{a} d h_{a}=d Q_{S}+d Q_{L}$

The enthalpy of moist air is given by:

$h_{a}=C_{p, d a} T_{a}+W\left(C_{p, s t}{ }^{s a t} T_{a}+\Delta h_{\text {evap }}\right)$

or

$d h_{a}=C_{p, d a} d T_{a}+d W\left(C_{p, s t}^{s a t} T_{a}+\Delta h_{\text {evap }}\right)+W C_{p, s t}{ }^{s a t} d T_{a}$ 
The term $\mathrm{dQ}_{\mathrm{s}}$ in Eq. (16) represents the sensible heat load, which is transferred from the desiccant solution to the air, due to their temperature difference and it can be written as follows:

$$
d Q_{S}=L h_{G}\left(T_{s}-T_{a}\right) d z
$$

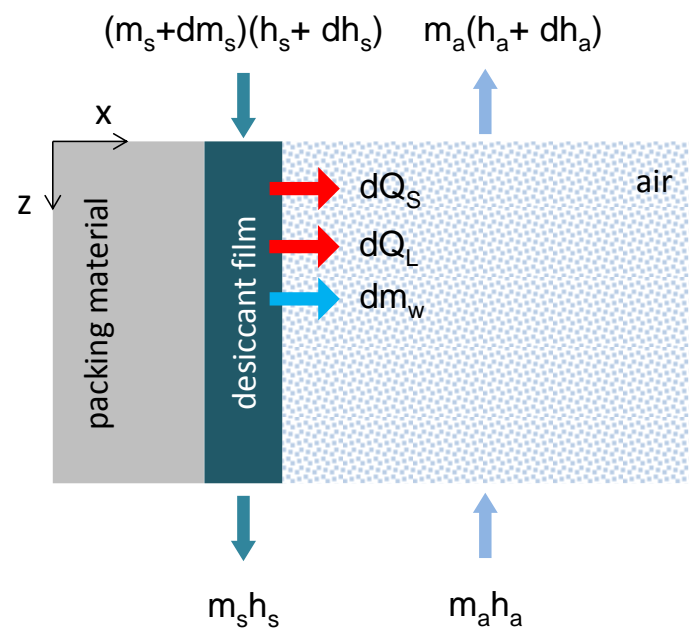

\section{Regeneration}

Figure 2. Energy and mass balance in an adiabatic regenerator.

whereas the latent heat load $d Q_{L}$ transferred from the desiccant solution to the air due to the water evaporation is:

$d Q_{L}=d \dot{m}_{s}\left(C_{p, s t}{ }^{s a t} T_{s}+\Delta h_{\text {evap }}\right)$

However, the specific heat capacity of the moist air is:

$C_{p, m a}=C_{p, d a}+W C_{p, s t}^{s a t}$

Substituting Eqs. (18), (19) and (20) into Eq. (16) and using Eqs. (12) and (21), the rate of air dry bulb temperature is obtained:

$$
\begin{aligned}
& \dot{m}_{a}\left[C_{p, d a} d T_{a}+d W\left(C_{p, s t}^{\text {sat }} T_{a}+\Delta h_{\text {evap }}\right)+W C_{p, s t}^{\text {sat }} d T_{a}\right]=d Q_{S}+d Q_{L} \\
& \frac{d T_{a}}{d z}=\frac{T_{s}-T_{a}}{C_{p, m a}}\left(\frac{L h_{G}}{\dot{m}_{a}}+C_{p, s t} \text { sat } \frac{d W}{d z}\right)
\end{aligned}
$$

\subsubsection{Liquid Desiccant Phase}

Combining Eq. (12) with Eq. (15) gives the mass of the water evaporated from the solution per unit height:

$$
\frac{d \dot{m}_{s}}{d z}=L K_{G}\left(W^{\mathrm{sat}}-W_{i n}\right)
$$

According to Figure 2,

$$
\left(\dot{m}_{s}+d \dot{m}_{s}\right)\left(h_{s}+d h_{s}\right)=\dot{m}_{s} h_{s}+d Q_{S}+d Q_{L}
$$

However, the term $d \dot{m}_{s} d h_{s}$ is negligibly small, so

$\dot{m}_{s} d h_{s}+h_{s} d \dot{m}_{s}=d Q_{S}+d Q_{L}$
Also, the enthalpy of the solution is given by the following expression:

$h_{s}=C_{p, s}\left(T_{s}-T_{s, i n}\right) \Rightarrow d h_{s}=C_{p, s} d T_{s}$

Taking into consideration of Eqs (12), (16), (18) and (27), Eq. (26) becomes:

$\dot{m}_{s} C_{p, s} d T_{s}+C_{p, s}\left(T_{s}-T_{s, i n}\right) \dot{m}_{a} d W=\dot{m}_{a}\left[C_{p, d d} d T_{a}+d W\left(C_{p, s t}{ }^{\text {sat }} T_{a}+\Delta h_{\text {evap }}\right)+W C_{p, s t}\right.$ sat $\left.d T_{a}\right]$

Differentiating Eq. (28) over height $z$ and using Eqs (15) and (23), the rate of change of desiccant temperature $T_{\mathrm{s}}$ is produced:

$$
\frac{d T_{s}}{d z}=\frac{\dot{m}_{a}}{\dot{m}_{s} C_{p, s}}\left[\left(-C_{p, s}\left(T_{s}-T_{s, i n}\right)+C_{p, s t}{ }^{s a t} T_{a}+\Delta h_{\text {evap }}\right) \frac{d W}{d z}+C_{p, m a} \frac{d T_{a}}{d z}\right]
$$

\subsubsection{System of Equations}

Finally, a system of five ordinary differential equations is constituted:

$$
\left\{\begin{array}{l}
\frac{d T_{a}}{d z}=\frac{T_{s}-T_{a}}{C_{p, m a}}\left[\frac{L h_{G}}{\dot{m}_{a}}+C_{p, s t} \text { sat } \frac{d W}{d z}\right] \\
\frac{d T_{s}}{d z}=\frac{\dot{m}_{a}}{\dot{m}_{s} C_{p, s}}\left[\left(-C_{p, s}\left(T_{s}-T_{s, i n}\right)+C_{p, s t}{ }^{s a t} T_{a}+\Delta h_{\text {evap }}\right) \frac{d W}{d z}+C_{p, m a} \frac{d T_{a}}{d z}\right] \\
\frac{d W}{d z}=\frac{L K_{G}}{\dot{m}_{a}}\left(W^{\text {sat }}-W_{i n}\right) \\
\frac{d \dot{m}_{s}}{d z}=\dot{m}_{a} \frac{d W}{d z} \\
\frac{d X}{d z}=-\frac{\dot{m}_{a}}{\dot{m}_{s}} X \frac{d W}{d z}
\end{array}\right\}
$$

The five-order Runge - Kutta was used to numerically integrate the above five ordinary differential equations by using a trial step at the midpoint of an interval to cancel out lower-order error terms. The model was developed using the Mathcad software [48] where all the thermodynamic characteristics of the regenerator are calculated from the point where the liquid desiccant is sprinkled till the end of the packing.

\section{Results and Discussion \\ 4.1 Validation of Mathematical Model}

Before proceeding to the examination of the effect of various operating parameters on the regeneration efficiency of the adiabatic packed column regenerator, the validation of the developed computational model should precede. For this purpose, experimental data from Fumo and Goswami [5, 6] were selected. Table 2 provides a comparison for a $\mathrm{LiCl}$ regenerator column packed with polypropylene Rauschert Hiflow rings.

Figure 3 shows the relative deviations of the predicted values from the corresponding experimental values for all 13 regeneration experiments. In the case of outlet dry bulb temperature, the results of the computational program are almost identical to the experimental ones. The maximum deviation is $-6.2 \%\left(-3.6^{\circ} \mathrm{C}\right)$ and the mean deviation is $-1.8 \%$ $\left(-1.0^{\circ} \mathrm{C}\right)$. A similar pattern is observed in the case of outlet humidity ratio. The maximum discrepancy is now $-6.8 \%$ ($\left.0.003 \mathrm{~kg}_{\mathrm{w}} / \mathrm{kg}_{\mathrm{d} \alpha}\right)$ and the mean deviation is still very small, at $-3.2 \%\left(-0.002 \mathrm{~kg}_{\mathrm{w}} / \mathrm{kg}_{\mathrm{d} \alpha}\right)$. The simulated outlet solution temperature differ as much as $1.4 \%\left(0.8{ }^{\circ} \mathrm{C}\right)$ from the experimental values, the average difference being only $0.2 \%$ 
$\left(0.1^{\circ} \mathrm{C}\right)$. The predictions of the model agree very well with the experimental findings in the case of outlet solution concentration; an average discrepancy of only $\pm 0.5 \%$ ($0.0017 \mathrm{~kg}_{\mathrm{LiCl}} / \mathrm{kg}_{\mathrm{s}}$ ) is seen. A similar observation can be made in the case of the water that is evaporated from the liquid desiccant solution; the maximum deviation is $6.6 \%(0.0001$ $\left.\mathrm{kg}_{\mathrm{w}} / \mathrm{kg}_{\mathrm{s}}\right)$, whereas the mean deviation is $2.6 \%(0.00005$ $\mathrm{kg}_{\mathrm{w}} / \mathrm{kg}_{\mathrm{s}}$ ). As it can be observed, the theoretical model shows very good agreement with the experimental results, having an excellent correspondence between most values.

Table 2. Comparison between the Experimental Data with the Simulated Results for a LiCl Regenerator.

\begin{tabular}{|c|c|c|c|c|c|c|}
\hline & $\mathrm{T}_{\mathrm{a}, \text { in }}$ & $\begin{array}{c}\mathrm{T}_{\mathrm{a}, \text { ou }} \\
\mathrm{t} \exp \\
{ }^{\circ} \mathrm{C}\end{array}$ & $\begin{array}{c}\mathrm{T}_{\mathrm{a}, \text { ou }} \\
\mathrm{t} \text {,sim } \\
{ }^{\mathrm{o}} \mathrm{C}\end{array}$ & $\mathrm{kg} \mathrm{kg}^{-1}$ & $\begin{array}{l}\mathrm{W}_{\mathrm{a} \text {,out, }} \\
\exp \\
\mathrm{kg} \mathrm{kg}^{-1}\end{array}$ & $\begin{array}{c}\mathrm{W}_{\mathrm{a} \text {,out, }} \\
\text { sim } \\
\mathrm{kg} \mathrm{kg}^{-1}\end{array}$ \\
\hline 1 & 30.4 & 58.9 & 60.5 & 0.01830 & 0.0579 & 0.05650 \\
\hline 2 & 30.1 & 59.3 & 57.4 & 0.01800 & 0.0532 & 0.05160 \\
\hline 3 & 29.8 & 57.5 & 53.9 & 0.01770 & 0.0488 & 0.04590 \\
\hline 4 & 35.1 & 58.5 & 58.2 & 0.01800 & 0.0551 & 0.05400 \\
\hline 5 & 40.0 & 58.9 & 59.0 & 0.01780 & 0.0548 & 0.05320 \\
\hline 6 & 30.2 & 57.6 & 57.0 & 0.01430 & 0.0513 & 0.05090 \\
\hline 7 & 29.4 & 58.5 & 56.4 & 0.02100 & 0.0541 & 0.05351 \\
\hline 8 & 30.3 & 57.6 & 57.1 & 0.01820 & 0.0507 & 0.04990 \\
\hline 9 & 29.9 & 59.0 & 57.8 & 0.01800 & 0.0556 & 0.05230 \\
\hline 10 & 30.0 & 55.8 & 54.7 & 0.01870 & 0.0447 & 0.04168 \\
\hline 11 & 29.7 & 62.6 & 60.9 & 0.01840 & 0.0666 & 0.06260 \\
\hline 12 & 29.7 & 57.6 & 56.0 & 0.01770 & 0.0542 & 0.05374 \\
\hline 13 & 30.3 & 57.9 & 57.4 & 0.01820 & 0.0501 & 0.04910 \\
\hline
\end{tabular}

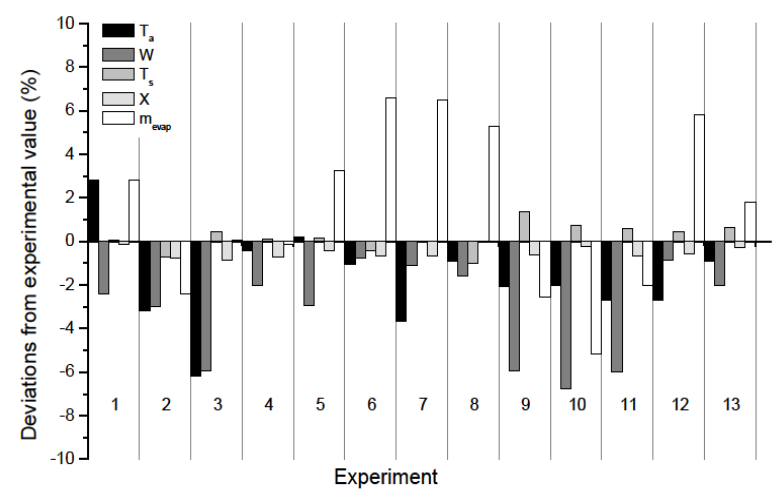

Figure 3. Relative deviations of the predicted values from the corresponding experimental values.

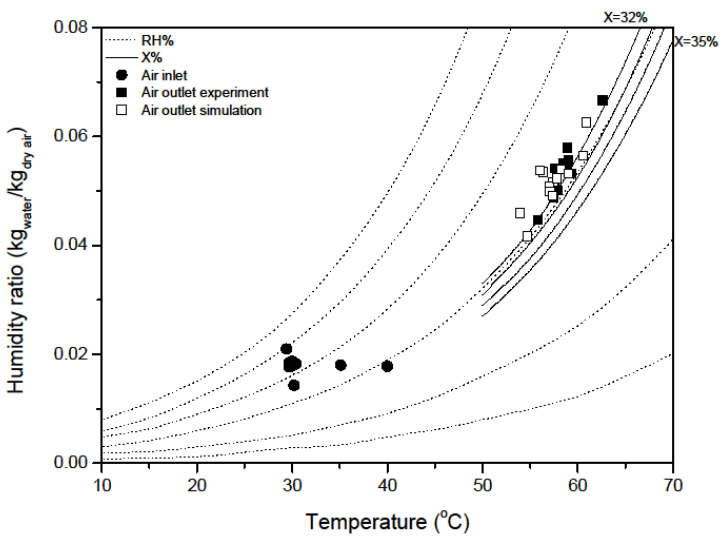

Figure 4.Initial and final states of the air passing through the regenerator.
The inlet and outlet conditions of both air and desiccant solution have been designed in a psychrometric chart, as seen in Figures 4 and 5. The vapor pressure expressions used to design these psychrometric charts are taken from Fumo and Goswami [5 6]. The proximity between the outlet values of the theoretical model and the outlet values of the experiments can be clearly seen in both charts.

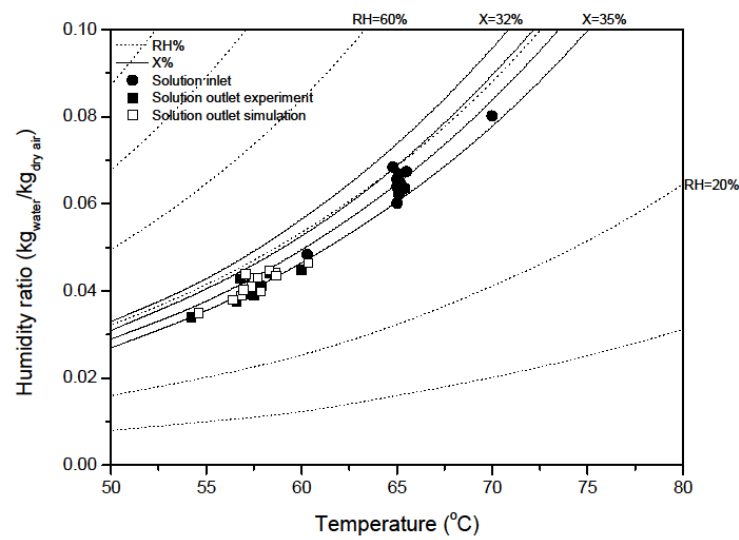

Figure 5. Liquid desiccant regeneration procedure.

Figure 5 also provides a simple explanation of the liquid desiccant regeneration procedure; the solution enters the regenerator at lower concentration and higher temperature, and exits at higher concentration and lower temperature, as a result of heat and mass transfer with the ambient air.

\subsection{Performance Indices}

The mass transfer performance of the regenerator is evaluated in terms of the regeneration rate and the regenerator efficiency. The regeneration rate $\left(\mathrm{kg}_{\mathrm{w}} / \mathrm{s}\right)$ is calculated by the following expression:

$\dot{m}_{w}=\dot{m}_{a}\left(W_{\text {out }}-W_{\text {in }}\right)$

Since liquid desiccant regeneration is a process driven by thermal energy, it is significant to have another index to evaluate the energy utilization efficiency for the liquid desiccant regeneration [49]. This index is called regeneration thermal efficiency and is defined as:

$n=\frac{\dot{m}_{a} \Delta h_{\text {evap }}\left(W_{\text {out }}-W_{\text {in }}\right)}{Q_{s}}$

where $\mathrm{Q}_{\mathrm{s}}$ is the total heat input to the desiccant solution, which is equal to the enthalpy increase of air and desiccant solution.

\subsection{Effects of Inlet Parameters on the Performance 4.3.1 Sensitivity Analysis}

A sensitivity analysis was performed on the inlet and outlet variables of both air and solution, such as temperature, humidity ratio, concentration and mass flow rate. This step was necessary in order to predict the effect of the independent variables (inputs $\mathrm{T}_{\mathrm{a}, \mathrm{in}}, \mathrm{W}_{\mathrm{in}}, \mathrm{m}_{\mathrm{a}}, \mathrm{T}_{\mathrm{s}, \mathrm{in}}, \mathrm{X}_{\mathrm{in}}, \mathrm{m}_{\mathrm{s}, \mathrm{in}}$, $\mathrm{K}_{\mathrm{G}}, \mathrm{Le}$ ) on the dependent variables (outputs $\mathrm{T}_{\mathrm{a} \text {,out }}, \mathrm{W}_{\text {out }}$, $\mathrm{RH}_{\text {out }}, \mathrm{T}_{\mathrm{s}, \text { out }}, \mathrm{X}_{\text {out }}, \mathrm{m}_{\mathrm{s}, \text { out }}, \mathrm{n}, \mathrm{m}_{\mathrm{w}}$ ). A multiple regression analysis has been also conducted, with the view to investigate the relationships between the variables and to ascertain the causal effect of one variable upon another. In other words, the regression was employed to estimate the 
quantitative effect of the independent variables upon the dependent variable that they influence.

For example, Table 3 shows the statistic results, after employing a regression analysis on the dependent variable $\mathrm{T}_{\mathrm{a}, \text { out }}$ for $\mathrm{LiCl}$ solution. The regression coefficients are the coefficients of the linear relationship between the $T_{a, o u t}$ and the independent variables.

Table 3. Regression Analysis.

\begin{tabular}{lccrr}
\hline \multicolumn{2}{c}{ Regression Statistics } & & $\begin{array}{r}\text { Regression } \\
\text { Coefficients }\end{array}$ & $\begin{array}{r}\text { Standardized } \\
\text { Regression } \\
\text { Coefficients }\end{array}$ \\
\hline Multiple R & 0.9632 & $\begin{array}{l}\text { Inters } \\
\text { ept }\end{array}$ & -11.4816 & - \\
R-Square & 0.9277 & $\mathrm{~T}_{\mathrm{a}, \text { in }}$ & 0.6282 & 0.5923 \\
Adjusted & 0.9277 & $\mathrm{~m}_{\mathrm{a}}$ & -112.4466 & -0.5587 \\
R square & & & & \\
Standard & 0.8462 & $\mathrm{~W}_{\mathrm{in}}$ & 24.1550 & 0.0080 \\
Error & & & & \\
& & $\mathrm{T}_{\mathrm{s}, \text { in }}$ & 0.2669 & 0.3689 \\
& & $\mathrm{~m}_{\mathrm{s} \text {,in }}$ & 1.9222 & 0.0427 \\
& & $\mathrm{X}_{\text {in }}$ & 6.8225 & 0.0271 \\
& & $\mathrm{~K}_{\mathrm{G}}$ & 0.5814 & 0.2209 \\
& & $\mathrm{Le}$ & 12.2289 & 0.1554 \\
\hline
\end{tabular}

It is difficult to say which of the independent variables is most important in determining the value of the dependent variable $T_{a, o u t}$, since the value of the regression coefficients depends on the units of measurement of the independent variables. So, the regression coefficients have been standardized and become "metric-free". Thus, the larger standardized regression coefficient of the independent variable, the greater influence on the dependent variable has. Figure 6 shows the standardized regression coefficients, for all desiccant solutions and for all dependent variables. Table 4 gives the linear regression equations for calculating the output thermodynamic properties of air and solution.

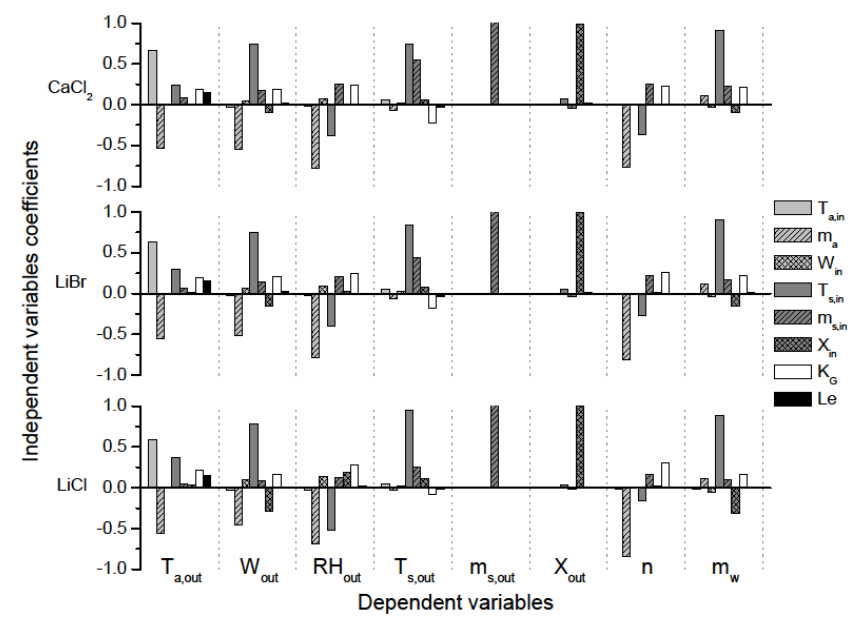

Figure 6. The standardized regression coefficients, for all desiccant solutions and for all dependent variables.

The quality of the linear fit, that is how well the regression line approximates the real data points, is represented by the coefficient of determination, $\mathrm{R}^{2}$. An $\mathrm{R}^{2}=$ 1 indicates that the regression line perfectly fits the data; however this is not guaranteed for all cases. So, to increase the precision of the $\mathrm{R}^{2}$, the adjusted- $\mathrm{R}^{2}$ is used instead, since it reflects both the number of independent variables in the model and the sample size.

The results of the sensitivity analysis show that the output conditions are found to be most sensitive to the solution inlet concentration, inlet mass flow rate and temperature as well as air inlet mass flow rate. The following paragraphs are dedicated to the thorough examination of the effect of each parameter separately.

\subsubsection{Desiccant Inlet Temperature}

Air outlet humidity ratio, regeneration rate and thermal efficiency increase with increasing desiccant inlet temperature. During regeneration, the partial water vapor pressure in the liquid desiccant solution is always higher than the water vapor pressure of the air, so that water is evaporated from the desiccant to the air. However, the increase in the solution inlet temperature results in a further increase in the partial water vapor pressure in the liquid desiccant solution. So, the difference between the partial water vapor pressure in the liquid desiccant solution and the water vapor pressure of the air is increased, enhancing thus the potential for mass transfer. This results in an increase of the air outlet humidity ratio (Figure 7) and consequently, in the increase of regeneration rate and thermal efficiency (Figure 8).

Table 4. Linear Regression Equations for Thermodynamic Properties of Air.

\begin{tabular}{|c|c|c|c|c|c|c|c|c|}
\hline \multicolumn{9}{|l|}{ LiCl } \\
\hline $\mathrm{a}$ & $\mathrm{b}$ & $\mathrm{c}$ & $\mathrm{d}$ & $\mathrm{e}$ & $\mathrm{f}$ & g & $\mathrm{h}$ & $\mathrm{i}$ \\
\hline-11.48 & 0.59 & -0.56 & 0.01 & 0.37 & 0.04 & 0.03 & 0.22 & 0.16 \\
\hline-0.01 & -0.04 & -0.46 & 0.09 & 0.79 & 0.08 & -0.30 & 0.16 & 0.00 \\
\hline 0.48 & -0.03 & -0.69 & 0.14 & -0.52 & 0.13 & 0.19 & 0.27 & 0.02 \\
\hline 2.95 & 0.05 & -0.03 & 0.02 & 0.95 & 0.25 & 0.11 & -0.09 & -0.01 \\
\hline 0.00 & 0.00 & 0.00 & 0.00 & -0.01 & 1.00 & 0.00 & 0.00 & 0.00 \\
\hline 0.00 & 0.00 & 0.00 & 0.00 & 0.03 & -0.02 & 1.00 & 0.01 & 0.00 \\
\hline 0.36 & -0.01 & -0.85 & 0.00 & -0.15 & 0.16 & 0.02 & 0.31 & 0.01 \\
\hline 0.00 & -0.01 & 0.11 & -0.06 & 0.89 & 0.09 & -0.32 & 0.16 & -0.01 \\
\hline \multicolumn{9}{|l|}{ LiBr } \\
\hline $\mathrm{a}$ & b & $\mathrm{c}$ & $\mathrm{d}$ & $\mathrm{e}$ & $\mathrm{f}$ & g & $\mathrm{h}$ & $\mathrm{i}$ \\
\hline-6.89 & 0.64 & -0.55 & 0.01 & 0.30 & 0.07 & 0.02 & 0.20 & 0.15 \\
\hline-0.07 & -0.03 & -0.52 & 0.06 & 0.76 & 0.14 & -0.15 & 0.21 & 0.03 \\
\hline 0.62 & -0.03 & -0.79 & 0.09 & -0.40 & 0.21 & 0.03 & 0.25 & 0.00 \\
\hline 15.11 & 0.05 & -0.06 & 0.02 & 0.84 & 0.44 & 0.08 & -0.18 & -0.04 \\
\hline 0.01 & 0.00 & 0.00 & 0.00 & -0.01 & 1.00 & 0.00 & 0.00 & 0.00 \\
\hline-0.01 & 0.00 & 0.00 & 0.00 & 0.05 & -0.04 & 1.00 & 0.02 & 0.00 \\
\hline 0.48 & -0.01 & -0.81 & 0.00 & -0.27 & 0.22 & 0.01 & 0.26 & 0.00 \\
\hline-0.01 & 0.01 & 0.12 & -0.04 & 0.91 & 0.16 & -0.16 & 0.22 & 0.02 \\
\hline \multicolumn{9}{|l|}{$\mathrm{CaCl}_{2}$} \\
\hline $\mathrm{a}$ & $\mathrm{b}$ & c & $\mathrm{d}$ & e & $\mathrm{f}$ & $\mathrm{g}$ & $\mathrm{h}$ & $\mathrm{i}$ \\
\hline-4.59 & 0.67 & -0.53 & 0.01 & 0.24 & 0.08 & 0.01 & 0.19 & 0.15 \\
\hline-0.10 & -0.03 & -0.55 & 0.05 & 0.74 & 0.18 & -0.10 & 0.19 & 0.02 \\
\hline 0.62 & -0.02 & -0.78 & 0.07 & -0.38 & 0.26 & 0.00 & 0.24 & 0.00 \\
\hline 21.04 & 0.06 & -0.07 & 0.02 & 0.74 & 0.56 & 0.06 & -0.22 & -0.04 \\
\hline 0.01 & 0.00 & 0.00 & 0.00 & -0.01 & 1.00 & 0.00 & 0.00 & 0.00 \\
\hline-0.01 & 0.00 & -0.01 & 0.00 & 0.07 & -0.04 & 0.99 & 0.02 & 0.00 \\
\hline 0.55 & -0.01 & -0.77 & 0.00 & -0.37 & 0.26 & 0.00 & 0.23 & 0.00 \\
\hline
\end{tabular}


In the present analysis, the increase in desiccant inlet temperature by $60 \%$ increases the regeneration rate, by $523 \%$ in the case of $\mathrm{LiCl}, 367 \%$ in $\mathrm{LiBr}$ and by $331 \%$ in $\mathrm{CaCl}_{2}$.

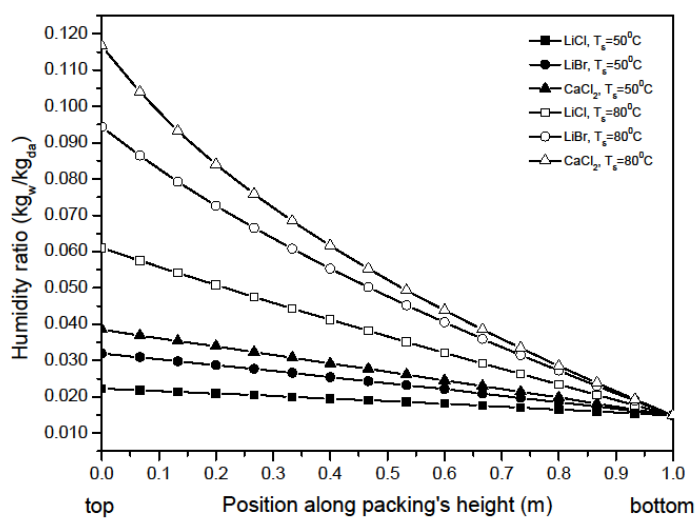

Figure 7. Air outlet humidity.

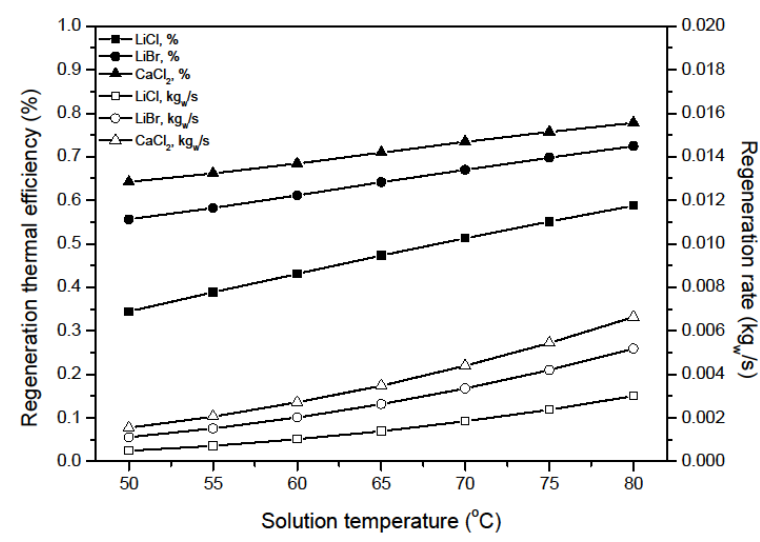

Figure 8. Regeneration rate and thermal efficiency.

All three figures also confirm that the $\mathrm{CaCl}_{2}$ has the best regenerator capacity among the other solutions. The reasoning is as follows: under the same temperature and concentration, the higher water partial vapour pressure, the greater ability a liquid desiccant has for water evaporation. Therefore, since $\mathrm{CaCl}_{2}$ has the highest water vapour pressure among the examined desiccants, it presents the highest regeneration capacity, whereas the lowest regeneration capacity should be attributed to $\mathrm{LiCl}$. Indeed, under specific initial conditions, its efficiency is $71 \%$ and its regeneration rate is $3.48 \mathrm{gr}_{\mathrm{w}} / \mathrm{s}$. At these conditions, the regenerator using $\mathrm{LiBr}$ has an efficiency of $64 \%$ and a regeneration rate of 2.63 $\mathrm{gr}_{\mathrm{w}} / \mathrm{s}$, whereas $\mathrm{LiCl}$ is the least favorable, with an efficiency of $47 \%$ and a regeneration rate of $1.39 \mathrm{gr}_{\mathrm{w}} / \mathrm{s}$ only.

The higher regeneration rate a solution experiences under higher inlet solution temperature is also obvious in the profile of the moisture content of the solution across the regenerator's height (Figure 9). Since the difference between the inlet and the outlet moisture content represents the mass of the water evaporated from the solution, higher inlet solution temperatures result in a steeper slope of the moisture content profile line.

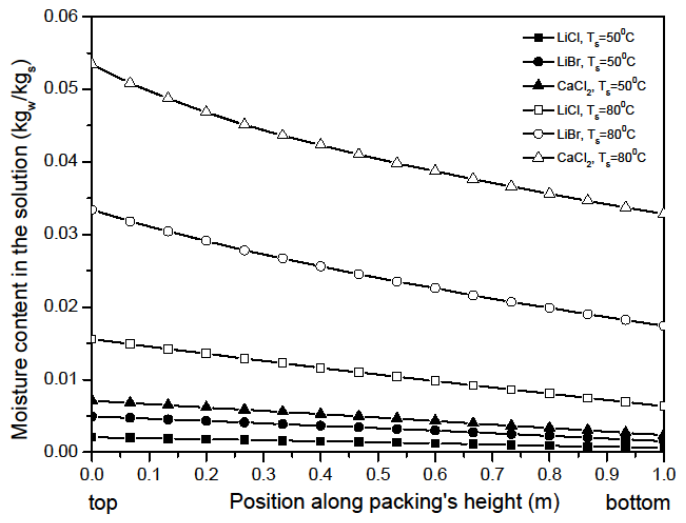

Figure 9. Moisture content of the solution across the regeneration height.

From the results shown in the above figures, it is suggested that higher inlet temperature of liquid desiccant should be preferred to get both higher energy utilization efficiency and more regeneration capacity.

\subsubsection{Air Flow Rate}

The variation of the regeneration rate as a function of the air flow rate is shown in Figure 10. Increasing the air flow rate by $300 \%$ increases the regeneration rate by about $27 \%$ for all three desiccant solutions, due to the increase in the mass transfer coefficient between the air and desiccant.

The increase in the regeneration rate due to the increase in air flow rate is also testified in Figure 11. Under higher air flow rates, there is less water content in the solution outlet, which means that more water has been evaporated, so the solution has been more effectively regenerated.

The efficiency of the $\mathrm{CaCl}_{2}$ regenerator is testified again, since a far larger amount of moisture seems to evaporate from $\mathrm{CaCl}_{2}$ solution than from $\mathrm{LiCl}$, regardless of the air mass flow rate. In fact, more water is evaporated from $\mathrm{CaCl}_{2}$ solution with low flow $\left(\mathrm{m}_{\mathrm{a}}=0.03265 \mathrm{~kg} / \mathrm{s}\right)$ than that of $\mathrm{LiCl}$ with high flow $\left(\mathrm{m}_{\mathrm{a}}=0.13060 \mathrm{~kg} / \mathrm{s}\right)$. Consequently, the choice between $\mathrm{CaCl}_{2}$ and $\mathrm{LiCl}$ may not count on the air flow rate, rather than other parameters. The choice, however, between $\mathrm{CaCl}_{2}$ and $\mathrm{LiBr}$ would appear more difficult, as $\mathrm{CaCl}_{2}$ solution with low flow $\left(\mathrm{m}_{\mathrm{a}}=0.03265 \mathrm{~kg} / \mathrm{s}\right)$ produces the approximately same result with $\mathrm{LiBr}$ with high flow $\left(\mathrm{m}_{\mathrm{a}}=0.13060 \mathrm{~kg} / \mathrm{s}\right)$. Other parameters as well as cost may provide the answer.

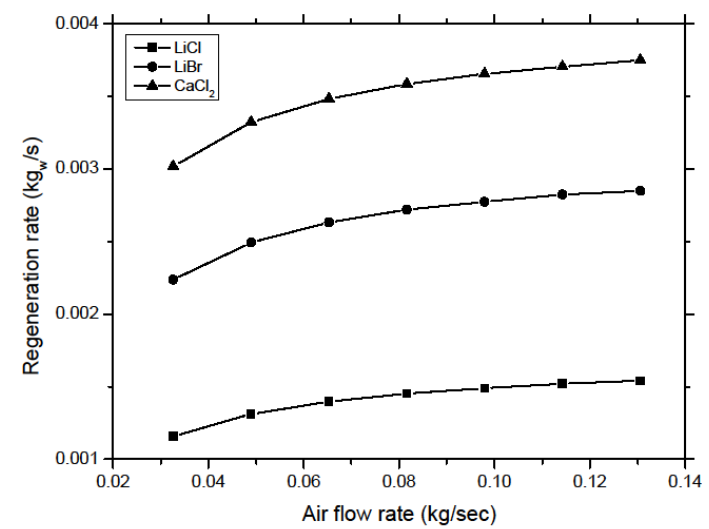

Figure 10. Variation of the regeneration rate as a function of the air flow rate. 


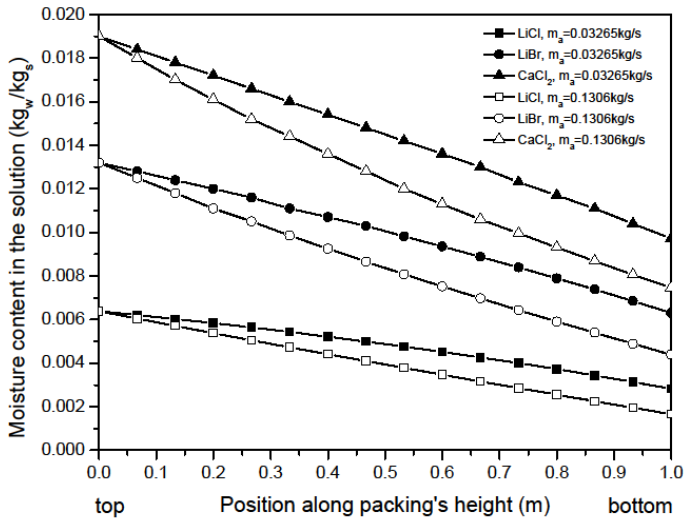

Figure 11. The increase in the regeneration rate due to the increase in air flow rate.

The effect of air flow rates on the pressure drop of both dry and irrigated bed is represented in Figure 12. As shown, the pressure drop increased with the increase of air flow rate; it remains though at very low levels.

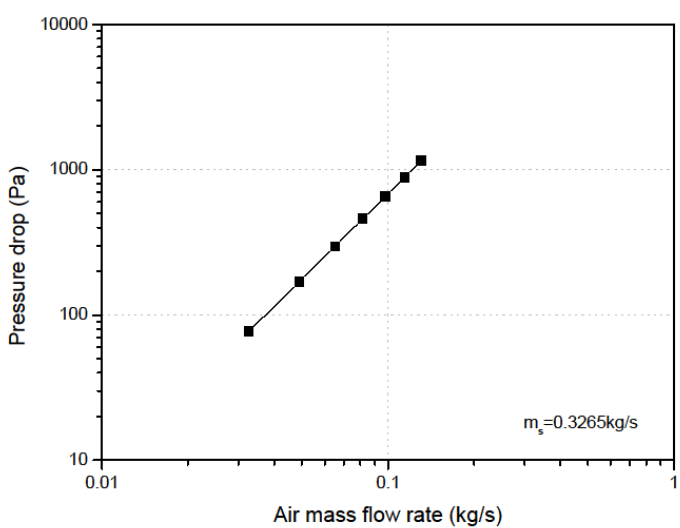

Figure 12. The effect of air flow rates on the pressure drop of both dry and irrigated bed.

\subsubsection{Desiccant Flow Rate}

The flow rate of the liquid desiccant is a controllable parameter for regenerator operation. Here the flow rate of the liquid desiccant varied from $0.16325 \mathrm{~kg} / \mathrm{s}$ to $0.6530 \mathrm{~kg} / \mathrm{s}$.

In the adiabatic regenerator, both regeneration thermal efficiency and regeneration rate improve significantly with the increase of desiccant flow rate. Since the flow rate of liquid desiccant determines the available heat for the regeneration, when the desiccant flow rate is kept high, the available heat is plenty and the solution does not have the time to cool down as it flows down through the bed. That is the reason why in Figure 13 higher solution flow rates result in more horizontal lines.

The higher desiccant mass flow rate, the higher temperatures will be maintained throughout the regeneration process and the higher water vapour pressure of the desiccant solution will be finally obtained.

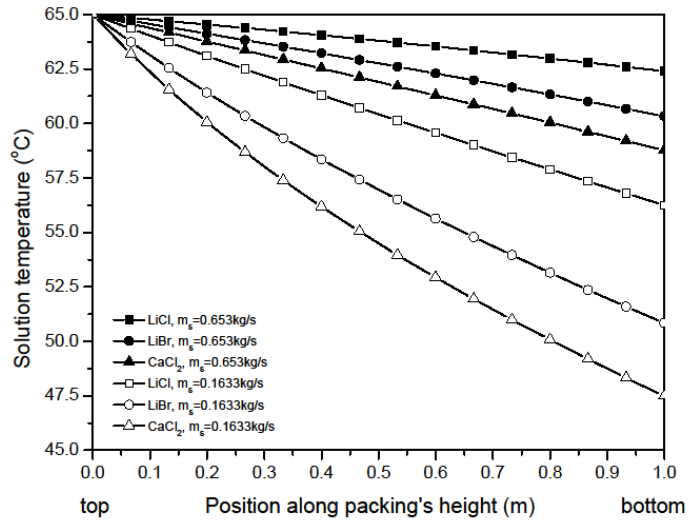

Figure 13. Solution temperature along packing's height.

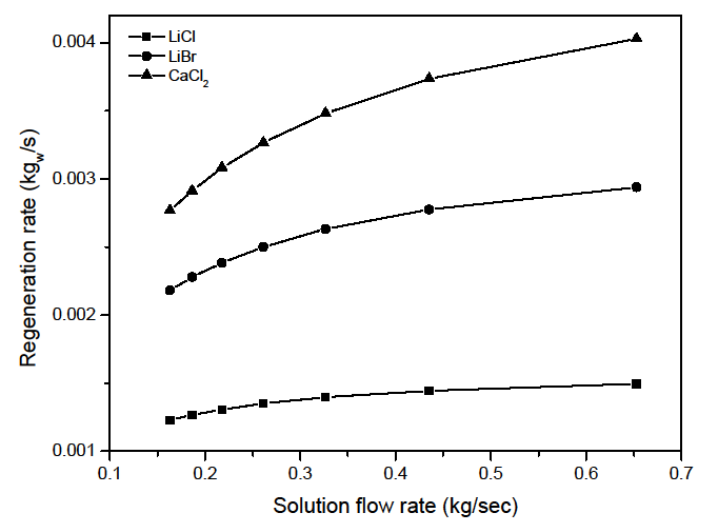

Figure 14. Regeneration rate vs solution flow rate.

This gives rise to a higher mass transfer potential for the regeneration processes, resulting in an increase in regeneration rate (Figure 14). In the present study, this phenomenon can be observed at desiccant flow rates of over $0.3 \mathrm{~kg} / \mathrm{sec}$. It has also been observed that a $75 \%$ increase in solution flow rate results in $18 \%$ increase in regeneration rate for $\mathrm{LiCl}$, in $26 \%$ increase for $\mathrm{LiBr}$ and in $31 \%$ increase for $\mathrm{CaCl}_{2}$.

However, when the desiccant flow rate is low, the available heat for the regeneration process is limited and the solution temperature decreases quickly after entering the regenerator, due to the heat and mass transfer with the air. The effect of regeneration is thus compromised. Under very small solution mass flow rates, the solution may be cooled dramatically, so that the water vapour pressure of desiccant solution may become lower than the vapor pressure of moist air. In such a case, the solution would actually be diluted.

\subsubsection{Solution Concentration}

Figure 15 shows the variation of the solution inlet concentration with respect to the humidity ratio distribution across the regenerator. $\mathrm{CaCl}_{2}$ solution appears to produce more humid air than $\mathrm{LiBr}$ and $\mathrm{LiCl}$, regardless of the solution inlet concentration. In fact, $\mathrm{CaCl}_{2}$ solution of $\mathrm{X}=0.36$ seems to be better than $\mathrm{LiBr}$ of $\mathrm{X}=0.28$. The same goes for $\mathrm{LiBr}$ and $\mathrm{LiCl}$. Under these circumstances, the desiccant inlet concentration seems to be far less important than the choice of the desiccant solution itself. 


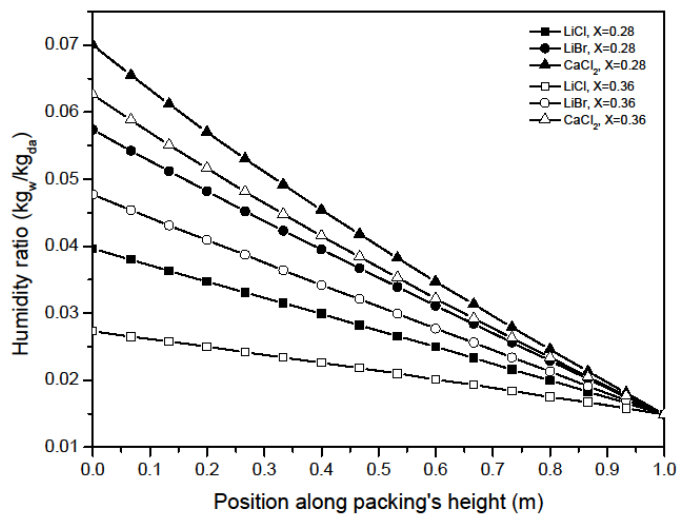

Figure 15. Solution inlet concentration.

The regeneration efficiency decreases with the increase of inlet desiccant concentration (Figure 16). This may be explained from the fact that vapor pressure of each desiccant is a function of the concentration. Therefore, as the solution concentration is increased, its vapor pressure is decreased. The potential for mass transfer is thus decreased, leaving a negative effect on the regeneration rate and efficiency. The model has predicted that a $29 \%$ rise in the solution inlet concentration results in $37 \%$ reduction in the regeneration efficiency of $\mathrm{LiCl}, 15 \%$ of $\mathrm{LiBr}$ and $10 \%$ of $\mathrm{CaCl}_{2}$.

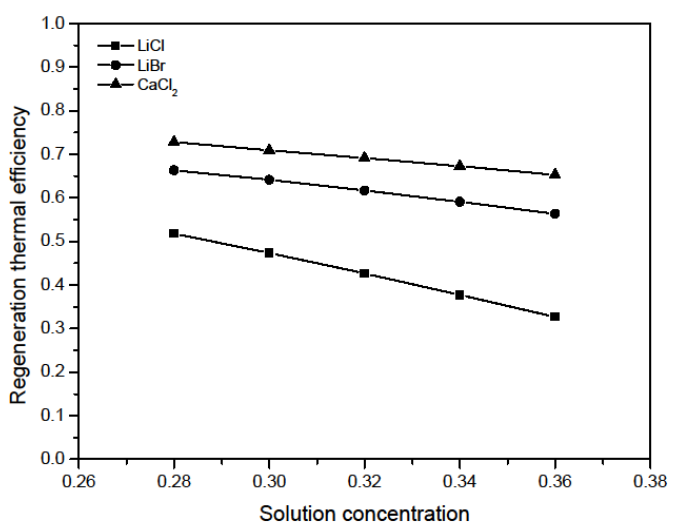

Figure 16. Regeneration demand efficiency.

\subsubsection{Type of Liquid Desiccant Solution}

$\mathrm{CaCl}_{2}$ has already shown clear regeneration performance precedence among the three desiccant solutions examined. The distribution though of the solution and air temperatures, as these are formed across the height of the packing, would give additional information.

Figure 17 shows that $\mathrm{CaCl}_{2}$ experiences the biggest difference between inlet and outlet solution temperature (65$54.2^{\circ} \mathrm{C}$ ), comparing to the other two materials. This released heat however, does not seem to be all absorbed by the upcoming air, since the air interacting with $\mathrm{CaCl}_{2}$ is not heated that much $\left(36-43.7^{\circ} \mathrm{C}\right)$. Most of this heat should therefore be used for the phase change of the water molecules, contained in the solution, from liquid to vapor.

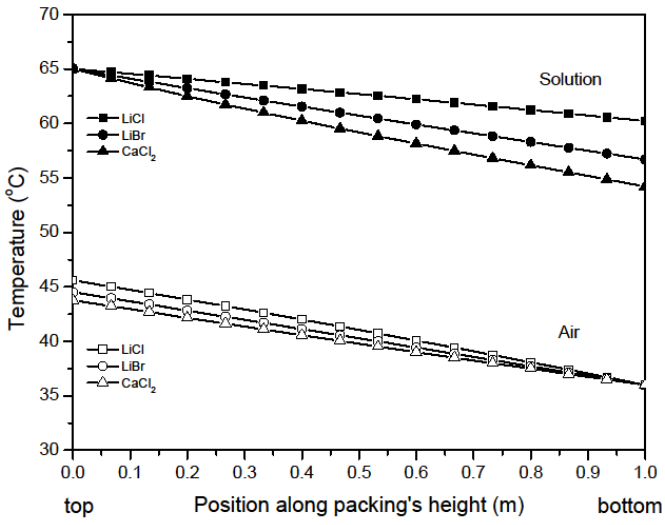

Figure 17. Inlet and outlet solutions temperature.

This is clearly seen in Figure 18 , where the $\mathrm{CaCl}_{2}$ convection load is the least of all solutions at the exit and at the same time, the $\mathrm{CaCl}_{2}$ evaporation load is the highest.

Correspondingly, $\mathrm{LiCl}$ has a smaller difference between inlet and outlet solution temperature $\left(65-60.2^{\circ} \mathrm{C}\right)$, whereas the air interacting with $\mathrm{LiCl}$ is significantly heated, (36$45.6^{\circ} \mathrm{C}$ ) compared to the other air streams. Therefore, the heat released from $\mathrm{LiCl}$ solution is mostly used for heating the air, rather than evaporating the moisture contained in the solution. That is the reason why the convection load of $\mathrm{LiCl}$ is the highest of all three materials, but its evaporation load is the least, as seen in Figure 18.

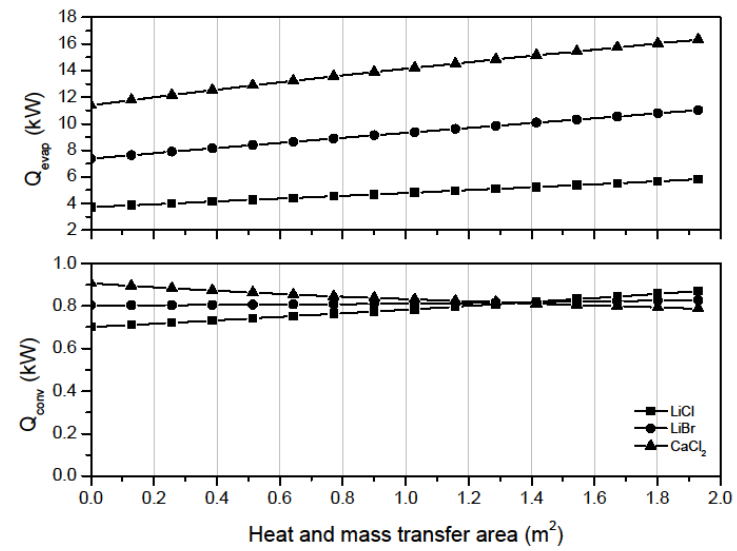

Figure 18. Convection and evaporation load.

It must be also noted here that in general, the difference between the desiccant outlet and inlet temperature is much higher than that of the air outlet and inlet temperature. This is due to the fact that the desiccant releases heat for both the phase change of water molecules (evaporation) and for balancing its temperature with the upcoming air (convection), so its temperature is substantially decreased. However, since the evaporation load causes only phase change and does not result in any temperature difference, the temperature of the air is heated only by the convection load.

The expressions for calculating the amount of heat transferred from the desiccant solution to the air in an adiabatic regenerator, due to convection and evaporation, are defined as:

$$
\begin{aligned}
& \dot{Q}_{\text {conv }}=h_{G} a\left(T_{s}-T_{a}\right) \\
& \dot{Q}_{\text {evap }}=K_{G} a \Delta h_{\text {evap }}\left(W^{\text {sat }}-W_{a}\right)
\end{aligned}
$$


In this study, the evaporation load ranges from 6 to 16 $\mathrm{kW}$, whereas the convection load ranges from 0.8 to $0.9 \mathrm{~kW}$, depending on the liquid desiccant material chosen.

As the desiccant solution flows down the regenerator, the amount of water evaporated increases, resulting in the increase of the evaporation load. The large regeneration capability of $\mathrm{CaCl}_{2}$ is also indicated by the significantly higher evaporation load, in comparison to $\mathrm{LiBr}$ and $\mathrm{LiCl}$.

\section{Conclusions}

One of the most critical questions in liquid desiccant air conditioning systems is the influence of the operational parameters on the regeneration performance. This study attempted to give an answer, by developing a coupled heat and mass transfer model to evaluate the performance of an adiabatic packed bed regenerator. The developed model showed an excellent agreement with the available experimental data from the literature. Following the model validation, effects of air and desiccant inlet parameters on the regenerator performance have been discussed. Some of the outcomes of this study are:

- According to the sensitivity analysis, the output conditions of the regenerator strongly depend on the inlet solution concentration change, but depend less on the inlet humidity ratio.

- $\quad$ For higher energy utilization efficiency and greater regeneration capacity, higher liquid desiccant inlet temperature is suggested.

- Higher desiccant mass flow rate results in higher mass transfer potential. This happens because when the desiccant mass flow rate is high, the desiccant temperature does not have enough time to decrease as it flows down through the bed. Since the temperature of the desiccant remains greater than the air, the desiccant surface vapor pressure remains higher than the air vapor pressure. This difference provides the mass transfer force.

- High system efficiency could be achieved under high air mass flow rates; however the air mass flow rate is a critical parameter only when choosing between $\mathrm{CaCl}_{2}$ and LiBr.

- A low inlet desiccant concentration would be also favorable for efficient regeneration, though the concentration seems to be less important than the choice of the desiccant solution itself.

- It has been observed that the heat released from $\mathrm{CaCl}_{2}$ solution is mostly used for the evaporation of moisture, whereas the heat released from $\mathrm{LiCl}$ is mostly used for heating the air.

- The high water vapor pressure has thus given to $\mathrm{CaCl}_{2}$ a considerable advantage over $\mathrm{LiBr}$ and $\mathrm{LiCl}$ for all the investigated parameters.

\section{Acknowledgements:}

The authors acknowledge with appreciation the Laboratory of Applied Thermodynamics, Thermal Engineering Section, School of Mechanical Engineering, National Technical University of Athens, for the support of the work on which this paper is based.

\section{Nomenclature}

$\begin{array}{ll}\mathrm{C}_{\mathrm{p}} & \begin{array}{l}\text { specific heat capacity at constant pressure } \\ (\mathrm{J} / \mathrm{kgK})\end{array} \\ \mathrm{D} & \text { diameter }(\mathrm{m}) \\ \mathrm{D} & \text { diffusion coefficient }\left(\mathrm{m}^{2} / \mathrm{s}\right) \\ \mathrm{h} & \text { enthalpy }\left(\mathrm{kJ} / \mathrm{kg}_{\mathrm{da}}\right)\end{array}$

$\mathrm{h}_{\mathrm{G}} \quad$ overall heat transfer coefficient $\left(\mathrm{W} / \mathrm{m}^{2} \mathrm{~K}\right)$

$\mathrm{k}$ thermal conductivity $(\mathrm{kW} / \mathrm{mK})$

$\mathrm{K}_{\mathrm{G}} \quad$ overall mass transfer coefficient $\left(\mathrm{kmol} / \mathrm{sm}^{2}\right.$ mole fraction)

$\mathrm{L} \quad$ length of packing (m)

Le Lewis number

$\dot{m} \quad$ mass flow rate $(\mathrm{kg} / \mathrm{s})$

$\dot{m}_{w} \quad$ regeneration rate $\left(\mathrm{kg}_{\mathrm{w}} / \mathrm{s}\right)$

M molecular weight $(\mathrm{kg} / \mathrm{kmol})$

$\mathrm{n} \quad$ regeneration thermal efficiency

$\mathrm{p} \quad$ pressure $(\mathrm{Pa})$

$\mathrm{Q} \quad$ heat $(\mathrm{kJ})$

$\dot{Q} \quad \operatorname{load}(\mathrm{kW})$

Re Reynolds number

Sc Schmidt number

$\mathrm{T}$ temperature $\left({ }^{\circ} \mathrm{C}\right)$

$V \quad$ superficial velocity (volumetric flow rate per column cross section) $(\mathrm{m} / \mathrm{s})$

W air humidity ratio $\left(\mathrm{kg}_{\mathrm{w}} / \mathrm{kg}_{\mathrm{da}}\right)$

$\mathrm{X} \quad$ salt concentration in solution $\left(\mathrm{kg}_{\mathrm{sal}} / \mathrm{kg}_{\mathrm{s}}\right)$

$\mathrm{Y}$ moisture content in solution $\left(\mathrm{kg}_{\mathrm{w}} / \mathrm{kg}_{\mathrm{s}}\right)$

$\mathrm{z} \quad$ column height $(\mathrm{m})$

$\Delta \mathrm{h}_{\text {evap }} \quad$ latent heat of vaporization for water $(\mathrm{kJ} / \mathrm{kg})$

\section{Greek symbols}

$\alpha \quad$ specific interfacial surface area of packing $\left(\mathrm{m}^{2} / \mathrm{m}^{3}\right)$

$\varepsilon \quad$ void fraction (bed porosity) $\left(\mathrm{m}^{3} / \mathrm{m}^{3}\right)$

$\lambda \quad$ liquid hold up in the packed bed $\left(\mathrm{m}^{3} / \mathrm{m}^{3}\right)$

$\mu \quad$ viscosity $(\mathrm{kg} / \mathrm{ms})$

$\rho$ density $\left(\mathrm{kg} / \mathrm{m}^{3}\right)$

\section{Subscripts}

a air

Atm atmospheric

Conv convection

da dry air

eq equivalent

exp experimental

evap evaporation

in inlet

L latent

ma moist air

out outlet

pack packing

S sensible

S solution

sim simulated

st steam

w water

\section{Superscripts}

sat saturated

\section{References:}

[1] E. Elsarrag, Performance study on a structured packed liquid desiccant regenerator, Solar Energy, 80, 16241631, 2006.

[2] Al. Lowenstein, M. H. Dean, Effect of regenerator performance on a liquid-desiccant air conditioner, ASHRAE Transactions, 98, 704-711, 1992. 
[3] P. Gandhidasan, Theoretical study of tilted solar still as a regenerator for liquid desiccants, Energy Conversion \& Management, 23, 97-101, 1983.

[4] X. Liu, Y. Jiang, J. Xia, X. Chang, Analytical solutions of coupled heat and mass transfer processes in liquid desiccant air dehumidifier/regenerator, Energy Conversion and Management, 48, 2221-2232, 2007.

[5] N. Fumo, Y. Goswami, "Study of an aqueous lithium chloride desiccant system Part II: Desiccant regeneration," in Proceedings of the Millennium Solar Forum 2000, Mexico City, Mexico, 2000, pp. 313-318.

[6] N. Fumo, Y. Goswami, Study of an aqueous lithium chloride desiccant system: air dehumidification and desiccant regeneration, Solar Energy, 72, 351-361, 2002.

[7] P. Gandhidasan, C. F. Kettleborough, M. Rifat Ullah, Calculation of Heat and Mass Transfer Coefficients in a Packed Tower Operating With a Desiccant-Air Contact System, Journal of Solar Energy Engineering, 108, 123-128, 1986.

[8] R. M. Lazzarin, A. Gasparella, G. A. Longo, Chemical dehumidification by liquid desiccants: theory and experiment, International Journal of Refrigeration, 22, 334-347, 1999.

[9] M. R. Conde, Properties of aqueous solutions of lithium and calcium chlorides: formulations for use in air conditioning equipment design, International Journal of Thermal Sciences, 43, 367-382, 2004.

[10] L. Zhang, E. Hihara, F. Matsuoka, C. Dang, Experimental analysis of mass transfer in adiabatic structured packing dehumidifier/regenerator with liquid desiccant, International Journal of Heat and Mass Transfer, 53, 2856-2863, 2010.

[11] S. V. Potnis, T. G. Lenz, Dimensionless Mass-Transfer Correlations for Packed-Bed Liquid-Desiccant Contactors, Industrial \& Engineering Chemistry Research, 35, 4185-4193, 1996.

[12] G. A. Longo, A. Gasparella, Experimental and theoretical analysis of heat and mass transfer in a packed column dehumidifier/regenerator with liquid desiccant, International Journal of Heat and Mass Transfer, 48, 5240-5254, 2005.

[13] G. O. G. Lof, T. G. Lenz, S. Rao, Coefficients of Heat and Mass Transfer in a Packed Bed Suitable for Solar Regeneration of Aqueous Lithium Chloride Solutions, Journal of Solar Energy Engineering, 106, 387-392, 1984.

[14] S. Patnaik, T. G. Lenz, G. O. G. Lof, Performance studies for an experimental solar open-cycle liquid desiccant air dehumidification system, Solar Energy, 44, 123-135, 1990.

[15] T. W. Chung, T. K. Ghosh, Comparison between Random and Structured Packings for Dehumidification of Air by Lithium Chloride Solutions in a Packed Column and Their Heat and Mass Transfer Correlations, Industrial \& Engineering Chemistry Research, 35, 192-198, 1996.
[16] X. H. Liu, K. Y. Qu, Y. Jiang, Empirical correlations to predict the performance of the dehumidifier using liquid desiccant in heat and mass transfer, Renewable Energy, 31, 1627-1639, 2006.

[17] Y. Yin, X. Zhang, Z. Chen, Experimental study on dehumidifier and regenerator of liquid desiccant cooling air conditioning system, Building and Environment, 42, 2505-2511, 2007.

[18] X. H. Liu, X. Q. Yi, Y. Jiang, Mass transfer performance comparison of two commonly used liquid desiccants: $\mathrm{LiBr}$ and $\mathrm{LiCl}$ aqueous solutions, Energy Conversion and Management, 52, 180-190, 2011.

[19] V. Oberg, D. Y. Goswami, Experimental study of the heat and mass transfer in a packed bed liquid desiccant air dehumidifier, Journal of Solar Energy Engineering, 120, 289-297, 1998.

[20] H. M. Factor, G. Grossman, A Packed Bed Dehumidifier / Regenerator for Solar Air Conditioning with Liquid Desiccants, Solar Energy, 24, 541-550, 1980.

[21] D. I. Stevens, J. E. Braun, S. A. Klein, An effectiveness model of liquid-desiccant system heat/mass exchangers, Solar Energy, 42, 449-455, 1989.

[22] A. Y. Khan, Sensitivity analysis and component modeling of a packed-type liquid desiccant system at partial load operating conditions, International Journal of Energy Research, 18, 643-655, 1994.

[23] A. Y. Khan, H. D. Ball, Development of a generalized model for performance evaluation of packed-type liquid sorbent dehumidifiers and regenerators, ASHRAE Transactions, 98, 525-533, 1992.

[24] X. Y. Chen, Z. Li, Y. Jiang, K. Y. Qu, Analytical solution of adiabatic heat and mass transfer process in packed-type liquid desiccant equipment and its application, Solar Energy, 80, 1509-1516, 2006.

[25] M. M. Elsayed, H. N. Gari, A. M. Radhwan, Effectiveness of heat and mass transfer in packed beds of liquid desiccant system, Renewable Energy, 3, 661$668,1993$.

[26] V. Martin, D. Y. Goswami, Heat and Mass Transfer in Packed Bed Liquid Desiccant Regenerators - An Experimental Investigation, Transactions of ASME, 121, 162-170, 1999.

[27] C. Ren, Y. Jiang, Y. Zhang, Simplified analysis of coupled heat and mass transfer processes in packed bed liquid desiccant-air contact system, Solar Energy, 80, 121-131, 2006.

[28] D. Babakhani, M. Soleymani, Simplified analysis of heat and mass transfer model in liquid desiccant regeneration process, Journal of the Taiwan Institute of Chemical Engineers, 41, 259-267, 2010.

[29] P. Gandhidasan, A simplified model for air dehumidification with liquid desiccant, Solar Energy, 76, 409-416, 2004.

[30] M. Raisul Islam, N. E. Wijeysundera, J. C. Ho, Heat and mass transfer effectiveness and correlations for counter-flow absorbers, International Journal of Heat and Mass Transfer, 49, 4171-4182, 2006. 
[31] R. Chengqin, J. Yi, T. Guangfa, Z. Yianpin, A characteristic study of liquid desiccant dehumidification/regeneration processes, Solar Energy, 79, 483-494, 2005.

[32] F. Xiao, G. Ge, X. Niu, Control performance of a dedicated outdoor air system adopting liquid desiccant dehumidification, Applied Energy, 88, 143-149, 2011.

[33] N. Audah, N. Ghaddar, K. Ghali, Optimized solarpowered liquid desiccant system to supply building fresh water and cooling needs, Applied Energy, 88, 3726-3736, 2011.

[34] D. Peng, Z. Xiaosong, An analytical model for coupled heat and mass transfer processes in solar collector/regenerator using liquid desiccant, Applied Energy, 88, 2436-2444, 2011.

[35] L. A. Cisternas, E. J. Lam, An analytic correlation of vapor pressure of aqueous and non-aqueous solutions of single and mixed electrolytes, Fluid Phase Equilibria, 53, 243-249, 1989.

[36] L. A. Cisternas, E. J. Lam, An analytic correlation for the vapor pressure of aqueous and non-aqueous solutions of single and mixed electrolytes: Part II application and extension, Fluid Phase Equilibria, 62, 11-27, 1991.

[37] E. D. Rogdakis, V. D. Papaefthimiou, D. C. Karampinos, A realistic approach to model $\mathrm{LiBr}-\mathrm{H} 2 \mathrm{O}$ smooth falling film absorption on a vertical tube, Applied Thermal Engineering, 23, 2269-2283, 2003.

[38] Papaefthimiou, V. D. Thermodynamic analysis of a LiBr-H2O absorption cooling system and cooling tower (Doctoral dissertation), National Technical University of Athens, Athens, 2004.

[39] V. D. Papaefthimiou, T. C. Zannis, E. D. Rogdakis, Thermodynamic study of wet cooling tower performance, International Journal of Energy Research, 30, 411-426, 2006.
[40] T. Uemura, Studies on the lithium chloride - water absorption refrigerating machine, Technology reports of the Kansai University, 9, 71-88, 1967.

[41] T. Uemura, S. Hasaba, Studies on the lithium bromide - water absorption refrigerating machine, Technology reports of the Kansai University, 6, 31-55, 1964.

[42] A. Kumar, V. S. Patwardhan, Prediction of vapour pressure of aqueous solutions of single and mixed electrolytes, The Canadian Journal of Chemical Engineering, 64, 831-838, 1986.

[43] V. S. Patwardhan, A. Kumar, A unified approach for prediction of thermodynamic properties of aqueous mixed-electrolyte solutions Part I: vapor pressure and heat of vaporization, AIChE Journal, 32, 1419-1428, 1986.

[44] K. Onda, H. Takeuchi, Y. Okumoto, Mass transfer coefficients between gas and liquid phases in packed columns, Journal of Chemical Engineering of Japan, 1, 56-62, 1968.

[45] R. E. Treybal, Mass Transfer Operations, 3rd ed. New York: McGraw-Hill Chemical Engineering Series, 1980.

[46] P. Gandhidasan, Prediction of pressure drop in a packed bed dehumidifier operating with liquid desiccant, Applied Thermal Engineering, 22, 1117-1127, 2002.

[47] A. Lowenstein, S. Slayzak, and E. Kozubal, "A zero carryover liquid-desiccant air conditioner for solar applications," in ASME International Solar Energy Conference ISEC2006, Denver, Colorado, 2006, paper nr ISEC2006-99079.

[48] PTC - Parametric Technology Corporation, MathCad Engineering Calculation Software, version 14.0.0.163, 2007.

[49] Y. Yin, X. Zhang, Comparative study on internally heated and adiabatic regenerators in liquid desiccant air conditioning system, Building and Environment, 45, 1799-1807, 2010. 